\title{
Refractoriness to inhaled sodium metabisulphite in subjects with mild asthma
}

\author{
I.D. Pavord, A. Wisniewski, A.E. Tattersfield
}

Refractoriness to inhaled sodium metabisulphite in subjects with mild asthma. I.D. Pavord, A. Wisniewski, A.E. Tattersfield. CERS Journals Ltd 1994.

ABSTRACT: Refractoriness occurs after challenges causing mediator release in asthma, by a mechanism which may involve inhibitory prostaglandins. Bronchoconstriction due to inhaled sodium metabisulphite is thought to involve neural pathways and to be independent of mediator release; whether it shows refractoriness is uncertain. We have sought evidence of refractoriness to the bronchoconstrictor response to inhaled sodium metabisulphite in subjects with mild asthma, and have tested the hypothesis that the development of refractoriness involves inhibitory prostaglandins.

Twelve subjects were challenged twice with a dose of sodium metabisulphite, previously shown to cause a $20 \%$ fall in forced expiratory volume in one second $\left(\mathrm{FEV}_{1}\right)$; the second challenge proceeded after recovery from the first. The response to sodium metabisulphite was expressed as the maximum $\%$ fall in $\mathrm{FEV}_{1}$ and area under the change in $\mathrm{FEV}_{1}$ curve over 20 min (AUC). Nine subjects were studied after double-blind treatment with oral indomethacin, $50 \mathrm{mg}$ t.d.s., or placebo, for 3 days.

The second sodium metabisulphite challenge caused significantly less bronchoconstriction than the first (mean maximum fall in FEV $_{1} 13.1$ and $24.3 \%$, respectively). Nine subjects showed a greater than $50 \%$ reduction in the response to the second challenge (mean reduction in AUC 73.7\%). In these subjects, indomethacin did not alter the response to the first sodium metabisulphite challenge, or the mean maximum fall in $\mathrm{FEV}_{1}$ in response to the second challenge (placebo 9.7\%, indomethacin $\mathbf{1 1 . 2 \%}$ ), but significantly increased the AUC of the second challenge (placebo 55, indomethacin 114). The mean reduction in AUC from first to second challenge was $78 \%$ with placebo and $48 \%$ with indomethacin.

We conclude that subjects with mild asthma show refractoriness to sodium metabisulphite. Inhibitory prostaglandins may be partly responsible, but are unlikely to have a major role.

Eur Respir J., 1994, 7, 50-54.
Respiratory Medicine Unit, City Hospital, Nottingham, UK.

Correspondence: I.D. Pavord

Respiratory Medicine Unit

City Hospital

Nottingham NG5 1PB

UK.

Keywords: Asthma

indomethacin

refractory

sodium metabisulphite

Received: January 271993

Accepted after revision August 81993

IDP is supported by the British Medical Research Council
Refractoriness, a reduced response to a second bronchoconstrictor challenge after recovery from the first, is well recognized with bronchoconstrictor challenges that act indirectly via mast cell mediator release, such as exercise and inhaled non-isotonic solutions and appears to be due to formation of inhibitory prostaglandins [1-3]. It is less clear whether refractoriness occurs following bronchoconstriction induced by sodium metabisulphite, a stimulus that is thought to act via release of sulphur dioxide $\left(\mathrm{SO}_{2}\right)$ and activation of neural pathways [4, 5].

Studies looking for evidence of refractoriness to sodium metabisulphite-induced bronchoconstriction have produced conflicting results [4-6], although there is clear evidence of refractoriness to the response to inhaled $\mathrm{SO}_{2}$ in asthma [7]. The aim of this study was to establish whether refractoriness occurs to the response to inhaled sodium metabisulphite in patients with asthma, and to assess the role of inhibitory prostaglandins, by studying the effect of the cyclooxygenase inhibitor indomethacin.

\section{Material and methods}

\section{Subjects}

Twelve subjects (10 male), aged 22-52 yrs, with mild asthma requiring inhaled therapy only, were recruited from the City Hospital asthma register. Six subjects were taking an inhaled corticosteroid regularly (beclomethasone $200-1,000 \mu \mathrm{g} \cdot \mathrm{day}^{-1}$ ), and all took an inhaled beta ${ }_{2}^{-}$ agonist as required. Beta ${ }_{2}$-agonists were withheld for $6 \mathrm{~h}$ before each visit; otherwise treatment was continued unchanged throughout the study. Eleven subjects were atopic, and one was a current smoker. All subjects had 
Table 1. - Refractoriness to sodium metabisulphite (MBS): subject details, with maximum fall in FEV $\mathrm{V}_{1}$ after first and second challenge with single $\mathrm{PD}_{20}$ dose of $\mathrm{MBS}$ on the assessment day and the two study days

\begin{tabular}{|c|c|c|c|c|c|c|c|c|}
\hline \multirow{3}{*}{$\begin{array}{l}\text { Subj } \\
\text { No. }\end{array}$} & \multirow{3}{*}{$\begin{array}{c}\mathrm{FEV}_{1} \\
\% \text { pred }\end{array}$} & \multirow{3}{*}{$\begin{array}{c}\text { Dose MBS } \\
\qquad \mu \mathrm{mol}\end{array}$} & \multicolumn{6}{|c|}{ Maximum fall in $\mathrm{FEV}_{1} \%$} \\
\hline & & & \multicolumn{2}{|c|}{ Assessment } & \multicolumn{2}{|c|}{ Placebo } & \multicolumn{2}{|c|}{ Indomethacin } \\
\hline & & & $1 \mathrm{st}$ & $2 n d$ & $1 \mathrm{st}$ & $2 \mathrm{nd}$ & $1 \mathrm{st}$ & 2nd \\
\hline 1 & 95 & 2.0 & 19 & 11 & 10 & 8 & 12 & 10 \\
\hline 2 & 98 & 3.0 & 25 & 13 & 25 & 8 & 29 & 14 \\
\hline 3 & 106 & 3.0 & 35 & 6 & 18 & 8 & 20 & 1 \\
\hline 4 & 76 & 0.5 & 42 & 13 & 41 & 17 & 33 & 22 \\
\hline 5 & 121 & 2.0 & 25 & 8 & 15 & 7 & 18 & 8 \\
\hline 6 & 99 & 6.0 & 27 & 8 & 21 & 7 & 18 & 13 \\
\hline 7 & 105 & 7.0 & 20 & 10 & 12 & 6 & 23 & 10 \\
\hline 8 & 100 & 12.0 & 15 & 4 & 29 & 2 & 5 & 6 \\
\hline 9 & 85 & 8.0 & 23 & 12 & 28 & 15 & 30 & 15 \\
\hline 10 & 100 & 2.0 & 22 & 15 & - & & - & - \\
\hline - & & & & & & & & \\
\hline 11 & 97 & 6.0 & 11 & 21 & - & - & - & - \\
\hline 12 & 105 & 1.7 & 27 & 37 & - & - & - & - \\
\hline Mean & 99 & $3.2 *$ & 24 & 13 & 22 & 10 & 21 & 11 \\
\hline SEM & 3 & & 2.4 & 2.5 & 3.3 & 1.8 & 2.9 & 2.0 \\
\hline
\end{tabular}

*: geometric mean. Subj: subject; $\mathrm{FEV}_{1}$ : forced expiratory volume in one second; \% pred: percentage of predicted.

a forced expiratory volume in one second $\left(\mathrm{FEV}_{1}\right)$ of more than $70 \%$ predicted (table 1 ). None gave a history of nonsteroidal anti-inflammatory drug-induced asthma, or bronchoconstricted in response to a test dose of indomethacin in the labatory. After verbal and written explanation of the study, subjects gave signed consent to participate. The protocol was approved by the City Hospital Ethics committee.

\section{Methods}

$\mathrm{FEV}_{1}$ was measured on a dry bellows spirometer (Vitalograph, Buckingham, UK) as the higher of two successive readings within $100 \mathrm{ml}$. The provocative dose of sodium metabisulphite required to cause a $20 \%$ fall in $\mathrm{FEV}_{1}\left(\mathrm{PD}_{20}\right)$ was established by giving increasing doses to a cumulative maximum of $128 \mu \mathrm{mol}$, using a MEFAR (Bresca, Italy) breath-activated dosimeter as described previously [8].

\section{Protocol}

In the first part of the study, subjects underwent a sodium metabisulphite challenge to determine the sodium metabisulphite $\mathrm{PD}_{20}$. They returned on a separate day, at the same time of day, for a single dose challenge with approximately the $\mathrm{PD}_{20}$ dose of sodium metabisulphite (table 1). $\mathrm{FEV}_{1}$ was measured before (baseline) and at $1,3,5,7$, and $10 \mathrm{~min}$ and then at 5 min intervals after the challenge. Subjects were rechallenged with the same dose of sodium metabisulphite after recovery $\left(\mathrm{FEV}_{1}>95 \%\right.$ baseline value). $\mathrm{FEV}_{1}$ was then measured at the same intervals for a further $20 \mathrm{~min}$.
Subjects who had a reduction in the area under the \% change in $\mathrm{FEV}_{1}$ over 20 min (AUC) at the second challenge of more than $50 \%$ were chosen to proceed to the second part of the study. Subjects were treated with oral indomethacin (50 mg t.d.s.), or matched placebo, for 3 days before each visit, in a double-blind, cross-over study. The last dose was taken $1 \mathrm{~h}$ before the subjects were challenged with two single $\mathrm{PD}_{20}$ doses of sodium metabisulphite, as described above.

\section{Analysis}

Sodium metabisulphite $\mathrm{PD}_{20}$ was calculated by linear interpolation of the log dose-response curve. The airway response to single dose challenge with sodium metabisulphite was expressed as \% change from the $\mathrm{FEV}_{1}$ recorded immediately before the challenge (baseline), and described as maximum $\%$ fall in $\mathrm{FEV}_{1}$ and AUC. Baseline $\mathrm{FEV}_{1}$, the maximum fall in $\mathrm{FEV}_{1}$ and AUC for the first and second challenge were compared within-subjects by paired t-tests, and differences calculated with $95 \%$ confidence intervals $(95 \% \mathrm{CI})$. A refractory index was derived, by expressing the difference between the AUC for first and second challenge as a percentage of the values for the first challenge. Mean indices were compared within-subjects by a paired t-test, and differences expressed as a mean with $95 \% \mathrm{CI}$.

\section{Results}

\section{Development of refractoriness}

Inhaled sodium metabisulphite caused dose-related bronchoconstriction in all subjects, the geometric mean 
Table 2. - Effect of indomethacin on refractoriness: area under the \% change in $\mathrm{FEV}_{1}$ curve over 20 min for first and second sodium metabisulphite challenge and refractory index (RI) on the assessment day and the two study days

\begin{tabular}{|c|c|c|c|c|c|c|c|c|c|}
\hline \multirow{3}{*}{$\begin{array}{l}\text { Subj } \\
\text { No. }\end{array}$} & \multicolumn{9}{|c|}{ Area under the $\%$ fall in $\mathrm{FEV}_{1}$ curve over 20 min } \\
\hline & \multicolumn{2}{|c|}{ Assessment } & \multirow{2}{*}{$\begin{array}{c}\text { RI } \\
\%\end{array}$} & \multicolumn{2}{|c|}{ Placebo } & \multirow{2}{*}{$\begin{array}{l}\mathrm{RI} \\
\%\end{array}$} & \multicolumn{2}{|c|}{ Indomethacin } & \multirow{2}{*}{$\begin{array}{l}\text { RI } \\
\%\end{array}$} \\
\hline & $1 \mathrm{st}$ & 2nd & & 1 st & 2nd & & 1 st & 2nd & \\
\hline 1 & 253 & 125 & 51 & 125 & 38 & 70 & 131 & 146 & -11 \\
\hline 2 & 398 & 128 & 68 & 325 & 122 & 62 & 413 & 126 & 69 \\
\hline 3 & 564 & 28 & 95 & 190 & 22 & 88 & 194 & 2 & 99 \\
\hline 4 & 508 & 60 & 88 & 623 & 109 & 83 & 461 & 228 & 51 \\
\hline 5 & 147 & 19 & 87 & 151 & 28 & 81 & 88 & 26 & 70 \\
\hline 6 & 204 & 67 & 56 & 106 & 42 & 61 & 116 & 88 & 24 \\
\hline 7 & 211 & 37 & 83 & 107 & 18 & 84 & 322 & 98 & 70 \\
\hline 8 & 77 & 11 & 86 & 246 & 4 & 98 & 94 & 79 & 15 \\
\hline 9 & 248 & 123 & 50 & 426 & 109 & 75 & 432 & 229 & 47 \\
\hline Mean & 290 & 66 & 74 & 255 & 55 & 78 & 250 & 114 & 48 \\
\hline SEM & 55 & 16 & 5.9 & 58 & 15 & 4.1 & 52 & 26 & 11.3 \\
\hline
\end{tabular}

For abbreviations see legend to table 1.

$\mathrm{PD}_{20}$ being $3.2 \mu \mathrm{mol}$. Challenge with a single dose of sodium metabisulphite on the assessment day caused the development of rapid bronchoconstriction (fall in $\mathrm{FEV}_{1}$ ), which reached a maximum between 1-3 min, and had usually recovered $\left(\mathrm{FEV}_{1}>95 \%\right.$ baseline) by 30 min. The mean maximum fall in $\mathrm{FEV}_{1}$ was $24 \%$ (table 1). After the second challenge, the mean maximum fall in $\mathrm{FEV}_{1}$ was $13 \%$ (mean difference $11 \%$; 95\% CI $3.6-18.9 \% ; \mathrm{p}<0.01)$. In nine of the 12 subjects, the refractory index was greater than $50 \%$ (mean $74 \%$ ) (table 2).

\section{Effect of indomethacin}

After placebo treatment the mean maximum fall was $22 \%$ after the first challenge, and $10 \%$ after the second challenge (table 1). All subjects remained refractory, and the mean refractory index was similar to the assessment value (78\%; table 2). Indomethacin treatment had no effect on the response to the first sodium metabisulphite challenge. There was no significant difference between placebo and indomethacin for the first challenge mean baseline $\mathrm{FEV}_{1}$ (3.50 and $3.42 \mathrm{l}$ ), time to recovery (26.1 and $27.2 \mathrm{~min}$ ), maximum \% fall in $\mathrm{FEV}$, (22 and 21\%), and AUC (255 and 250) tables 1 and 2, and fig. 1). There was also no significant difference between placebo and indomethacin for baseline FEV, (3.37 vs $3.31 l$ ) and maximum \% fall in $\mathrm{FEV}_{1}$ (10 vs $11 \%$ ) for the second challenge. The AUC following the second challenge was, however, significantly greater with indomethacin treatment $(114$; mean difference from placebo 59; 95\% CI 17.5-100.6; p<0.02) (table 2). The mean refractory index $(48 \%)$ was significantly less than that following placebo (mean difference $30 \%$; $95 \%$ CI $3.9-55.6 \% ; \mathrm{p}=0.03$ ). Four subjects had a refractory index of less than $50 \%$ after indomethacin treatment (table 2).

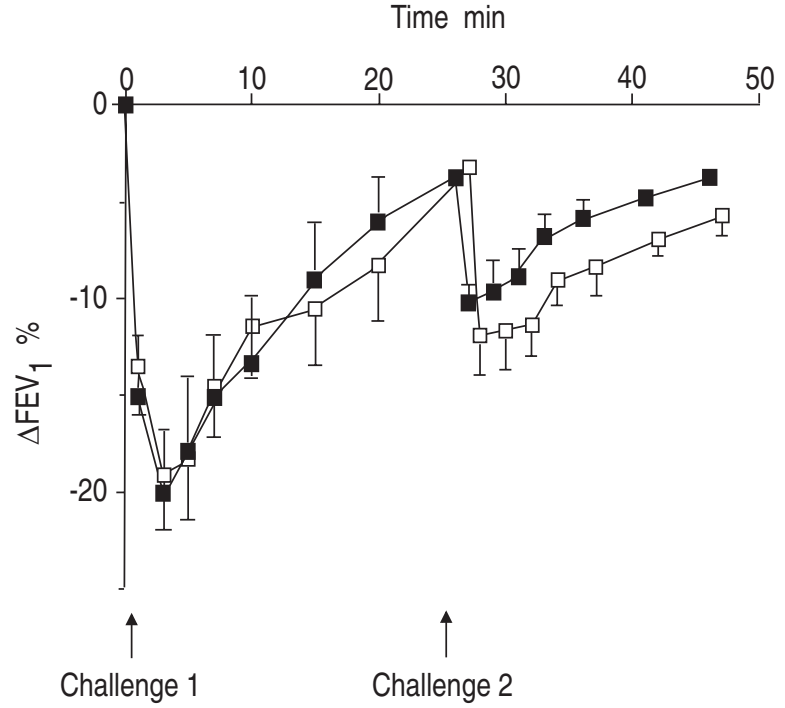

Fig. 1. - Mean (SEM) change in $\mathrm{FEV}_{1}$, expressed as percentage fall from baseline, after first and second sodium metabisulphite challenge with placebo $(\square)$ and indomethacin $(\square)$ treatment. FEV ${ }_{1}$ : forced expiratory volume in one second.

\section{Discussion}

We have shown evidence of refractoriness to the bronchoconstrictor response to a repeat single inhaled dose of sodium metabisulphite in 12 subjects with mild asthma. Nine subjects showed a greater than $50 \%$ reduction in response to a second sodium metabisulphite challenge.

Studies looking for evidence of refractoriness to sodium metabisulphite in asthma have produced conflicting results. NichOL et al. [4] showed refractoriness in five subjects rechallenged with a single dose of sodium metabisulphite $45 \mathrm{~min}$ after the first challenge, whereas 
two studies using repeated cumulative or sequential dose challenges found no evidence of refractoriness [5, 6]. Refractoriness appears, therefore, to be less apparent when increasing, sequential doses of sodium metabisulphite are given, suggesting that refractoriness is starting to develop during the first challenge. The differences between studies might also be due to methodological differences. In all previous studies, the repeat challenge has been performed at fixed times after the first challenge [4-6]. This can lead to wide differences in baseline lung function before the first and second challenge, or a reduction in refractoriness when there is a long interval between challenges. We attempted to get over these problems by performing the second challenge as soon as the $\mathrm{FEV}_{1}$ had returned to $95 \%$ of the baseline value before the first challenge. The second baseline $\mathrm{FEV}_{1}$ was slightly lower than the first, so that by using it as baseline for the second challenge the degree of refractoriness may have been overestimated. This would not, however, affect the comparison between placebo and indomethacin treatment, since recovery had occurred to a similar degree before the second challenge with both treatments.

Sodium metabisulphite is thought to cause bronchoconstriction by releasing $\mathrm{SO}_{2}[1,2]$, since the bronchoconstrictor response to inhaled $\mathrm{SO}_{2}$ is similar in time course to that of sodium metabisulphite $[4,9]$, and $\mathrm{SO}_{2}$ is released by sodium metabisulphite solutions in a dose dependent manner [5]. Histamine release is unlikely to contribute to bronchoconstriction, since the response to sodium metabisulphite is not inhibited by terfenadine [10]. Our demonstration that indomethacin has no effect on the initial response to sodium metabisulphite suggests that production of constrictor prostaglandins is also unimportant.

Animal studies suggest that $\mathrm{SO}_{2}$ causes vagally-mediated bronchoconstriction [9]. Such a pathway would fit with the rapid onset and lack of effect of terfenadine and indomethacin on sodium metabisulphite-induced bronchoconstriction in asthma. However, antimuscarinic agents have an inconsistent effect on sodium metabisulphite-induced bronchoconstriction $[4,10]$, suggesting that nonadrenergic, noncholinergic (NANC) excitatory nerve pathways may be important [4]. Refractoriness to sodium metabisulphite could, therefore, result from a reduction in neural activity or a reduction in the airway smooth muscle response to released neurotransmitters. Loss of airway smooth muscle responsiveness is less likely, since the bronchoconstrictor response to the direct airway smooth muscle agonists, histamine and methacholine, is unchanged after recovery from sodium metabisulphite challenge $[5,6]$.

A reduction in neural activity may be due to depletion of neurotransmitters, as has been shown to occur with neuropeptide release in animal studies after repeated neural stimulation [11]. Stimulation of sensory nerve endings by sodium metabisulphite in asthma might have a similar effect, and would provide a plausible explanation for the development of refractoriness. Our finding of a small reduction in refractoriness in subjects treated with indomethacin suggests that inhibitory prostaglandins may be playing a role. The most likely candidate is prostaglandin $\mathrm{E}_{2}\left(\mathrm{PGE}_{2}\right)$ since this is produced by human airway epithelium [12], and smooth muscle [13], and studies on canine and human airway smooth muscle in vitro show that low concentrations of $\mathrm{PGE}_{2}$ inhibit both cholinergic and noncholinergic neurally-induced contractions $[14,15]$. Furthermore, inhaled $\mathrm{PGE}_{2}$ provides very effective protection against sodium metabisulphiteinduced bronchoconstriction in subjects with asthma [8].

The inhibitory effect of indomethacin on the development of refractoriness was small, however, and was only evident with AUC data, which would not support a major role for prostaglandins. Inhibition of prostaglandin production should have been adequate, since similar doses of indomethacin have been shown to inhibit production of pulmonary cyclooxygenase products in response to allergen $[16,17]$, and markedly attenuate the refractory period after exercise challenge in subjects with asthma [1].

Acknowledgements: The authors thank S. Pacey for coding and randomizing the drugs and J. Williams for help with subject recruitment. The helpful advice of J. Britton and A. Knox is much appreciated.

\section{References}

1. O'Byrne PM, Jones GL. - The effect of indomethacin on exercise-induced bronchoconstriction and refractoriness after exercise. Am Rev Respir Dis 1986; 134: 6972 .

2. Mattoli S, Foresi A, Corbo GM, Valente S, Ciappi G. The effect of indomethacin on the refractory period occurring after the inhalation of ultrasonically nebulized distilled water. J Allergy Clin Immunol 1987; 79: 678-683.

3. O'Hickey SP, Hawksworth RJ, Rees PJ, Lee TH. - Effect of indomethacin on the refractory period to hypertonic saline-induced bronchoconstriction. Am Rev Respir Dis 1990; 141: A655.

4. Nichol GM, Nix A, Chung KF, Barnes PJ. - Characterisation of bronchoconstrictor responses to sodium metabi-sulphite aerosol in atopic subjects with and without asthma. Thorax 1989; 44: 1009-1014.

5. Wright W, Zhang YG, Salome CM, Woolcock AJ. Effect of inhaled preservatives on asthmatic subjects. I. Sodium metabisulfite. Am Rev Respir Dis 1990; 141: 1400-1404.

6 O'Connor BJ, Chen-Wordsdell M, Ridge SM, Fuller RW, Barnes PJ. - Inhaled sodium metabisulphite does not show immediate tachyphylaxis in asthma. Thorax 1990; 45: 786.

7. Sheppard D, Epstein J, Bethel RA, Nadel JA, Boushey HA. - Tolerance to sulfur dioxide-induced bronchoconstriction in subjects with asthma. Environ Res 1983: 30: 412-419.

8. Pavord ID, Wisniewski A, Mathur R, Wahedna I, Knox A, Tattersfield AE. - Effect of inhaled prostaglandin $\mathrm{E}_{2}$ on bronchial reactivity to sodium metabisulphite and methacholine in subjects with asthma. Thorax 1991; 46: 633-637.

9. Nadel JA, Salem H, Tamplin B, Tokiwa Y. - Mechanism of bronchoconstriction during inhalation of sulfur dioxide. J Appl Physiol 1965; 20: 164-167.

10. Dixon CMS, Ind PW. - Metabisulfite induced bronchoconstriction: mechanisms. Am Rev Respir Dis 1988; 137: 238. 
11. Brokaw JJ, Hillenbrand CM, White G, McDonald DM. - Mechanism of tolerance associated with neurogenic plasma extravasation in the rat trachea. Am Rev Respir Dis 1990; 141: 1434-1440.

12. Churchill L, Chilton FH, Resau JH, Bascom R, Hubbard WC, Proud D. - Cyclooxygenase metabolism of endogenous arachidonic acid by cultured human tracheal epithelial cells. Am Rev Respir Dis 1989; 140: 449459.

13. Haye-Legrand I, Cerrina J, Raffestin B, et al. - Histamine contractions of isolated human airway smooth muscle preparations: role of prostaglandins. J Pharmacol Exp Ther 1986; 239: 536-541.

14. Ullman A, Ciabattoni G, Lofdahl CG, Lindren A, Svedmyr N, Skoogh BE. - Epithelium-derived $\mathrm{PGE}_{2}$ inhibits the contractile response to cholinergic stimulation in isolated ferret trachea. Pulm Pharmacol 1990; 3: $155-160$.

15. Ito I, Suzuki H, Aizawa H, Hirose T, Hakoda H. Prejunctional inhibitory action of prostaglandin $\mathrm{E}_{2}$ on excitatory neuro-effector transmission in the human bronchus. Prostaglandins 1990; 39: 639-655.

16. Dworski R, FitzGerald G, Roberts L, Oates J, Schwartz L, Sheller JR. - Eicosanoid formation in atopic human lung: effect of indomethacin. Am Rev Respir Dis 1988; 137: 375.

17. Sladek K, Dworski R, Fitzgerald GA, et al. - Allergenstimulated release of thromboxane $\mathrm{A}_{2}$ and leukotriene $\mathrm{E}_{4}$ in humans. Effect of indomethacin. Am Rev Respir Dis 1990; 141: 1441-1445. 